\title{
Exchange Rate Returns and Volatility: The Role of Time-Varying Rare Disaster Risks*
}

\author{
Rangan Gupta ${ }^{\mathrm{a}, \mathrm{b}}$, Tahir Suleman ${ }^{\mathrm{c}, \mathrm{d}}$ and Mark E. Wohar,,f,*
}

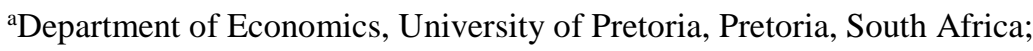

' IPAG Business School, Paris, France;

${ }^{\mathrm{c} S c h o o l}$ of Economics and Finance, Victoria University of Wellington, Wellington, New Zealand;

${ }^{\mathrm{d}}$ School of Business, Wellington Institute of Technology, Wellington, New Zealand;

${ }^{\mathrm{e}}$ College of Business Administration, University of Nebraska at Omaha, Omaha, NE, USA;

${ }^{\mathrm{f}}$ School of Business and Economics, Loughborough University, Leicestershire, UK
\end{abstract}

*Correspondence to: Mark E. Wohar,

College of Business Administration, University of Nebraska at Omaha, 6708 Pine Street, Omaha, NE 68182,

USA; School of Business and Economics, Loughborough University, Leicestershire LE11 3TU, UK

$\underline{\text { mwohar@unomaha.edu }}$

\begin{abstract}
This paper provides empirical evidence to the theoretical claim that rare disaster risks have predictability for exchange rate returns and volatility using a nonparametric quantile-based methodology. Using dollar-based exchange rates for Brazil, Russia, India, China, and South Africa, the quantile-causality test shows that indeed rare disaster-risks affects both returns and volatility over the majority of their respective conditional distributions. In addition, these effects are much stronger when compared to those using the British pound, especially in terms of currency returns.
\end{abstract}

Keywords: Exchange Rate Returns and Volatility; Rare Disasters; Nonparametric Quantile Causality.

JEL Codes: C22, C58, G14, G15.

\footnotetext{
* We would like to thank an anonymous referee, the Associate Editor, and the Editor (Professor Christopher J. Adcock) for many helpful comments. However, any remaining errors are solely ours.
} 


\section{Introduction}

In a recent paper, based on the earlier works of Rietz (1988) and Barro (2006), Farhi and Gabaix (2016) propose a new model of exchange rates, which shows that the possibility of rare but extreme disasters is an important determinant of movements (returns and volatility) of exchange rates, with the effect being particularly strong (especially when it comes to returns) for currencies that are perceived to be more risky.

An obstacle, however, for empirical verification of predictions of rare disaster theoretical models, which in turn are generally calibrated, is that individual countries rarely face actual major disasters. To avert this small sample problem inherent in the use of actual rare disasters, Berkman et al. (2011) recommend focusing on a much larger sample of potential disasters, i.e., international political crises that are likely to cause changes in perceived rare disaster probabilities. Following the approach in Berkman et al. $(2011,2017)$, our source of events (i.e., changes in disaster probability), is a detailed database of all international political crises (464 to be exact) that occurred during the period 1918 to 2013, derived from the International Crisis Behavior project (ICB) database developed by the Center for International Development and Conflict Management.

Given this database, the goal of this paper is to examine, the predictive power of raredisaster risks for the return and volatility dynamics of dollar-based exchange rates of Brazil, Russia, India, South Africa, using monthly data over 1918:01-2013:12, and for China covering the period 1948:09-2013:12. The choice of these five emerging countries, popularly known as the BRICS, is obvious, not only due to their importance in the global economy (Mensi et al., 2014, 2016), but also because of Farhi and Gabaix's (2016) prediction that rare disaster risks are likely to affect riskier currencies, which can understandably be associated with emerging markets, relative to a safe-haven. As a matter of comparison, we also conduct the analysis of the British pound over 1918:01-2013:12, with the presumption that it is less 
likely to be affected by rare-disaster risks, especially in terms of its returns.

To achieve our objective, we conduct the predictability analysis based on the $k$-th order nonparametric causality-in-quantiles test recently developed by Balcilar et al. (2016). As indicated by Balcilar et al. (2016), the causality-in-quantile approach has the following novelties: Firstly, it is robust to misspecification errors as it detects the underlying dependence structure between the examined time series. Secondly, via this methodology, we are able to test for not only causality-in-mean (1st moment), but also causality that may exist in the tails of the distribution of the variables. Finally, we are also able to investigate causality-in-variance and, thus, study higher-order dependency. Understandably, this test is comparatively superior to the conditional mean-based standard linear Granger causality test, as it not only studies the entire conditional distribution of both returns and volatility, but, being a data-driven nonparametric approach, also controls for misspecification due to nonlinearity - a widely observed characteristic in exchange rates (Rapach and Wohar, 2006; Plakandaras et al., 2015, 2017). In this regard, while nonlinear causality tests of Hiemstra and Jones. (1994), and Diks and Panchenko $(2005,2006)$ can control for misspecification due to nonlinearity, they are restricted to the conditional mean of the first-moment of exchange rates only. Finally, the causality-in-quantiles test is also superior to the standard GARCH models, since the latter specifies a linear relationship between returns and volatility with the predictors being studied, besides being restricted to the analysis of the conditional mean.

To the best of our knowledge, this is the first paper that evaluates the predictive power of rare disaster risks over exchange rate returns and volatility based on a nonparametric causality-in-quantiles framework. Previewing our results, we find that, when volatility (risk) in BRICS markets is low, the rare disaster risks tend to have a bigger impact than when we look at the upper quantiles of squared returns, capturing higher volatility, and hence, perhaps stronger monetary policy response. In terms of returns, the strength of the impact or rare 
disaster risks ... are generally lower at extreme ends of the conditional distribution, with the effects showing a declining trend as the quantiles increase. Unlike the emerging markets, for the UK however, the strongest effects of rare disaster risks on both returns, and volatility in particular, is felt around the median.

The rest of this paper is organized as follows: Section 2 describes the econometric frameworks involving the higher-moment nonparametric causality-in-quantiles test. Section 3 presents the data and discusses the empirical results, with Section 4 conducting some robustness analysis. Finally, Section 5 concludes the paper.

\section{Econometric Framework}

In this section, we briefly present the methodology for the detection of nonlinear causality via a hybrid approach as developed by Balcilar et al. (2016), which in turn is based on the frameworks of Nishiyama et al. (2011) and Jeong et al. (2012). We start by denoting exchange rate returns by $y_{t}$ and the predictor variable (in our case, various types of rare disaster risk-related events, as discussed in detail in the data segment) as $x_{t}$. We further let $Y_{t-1} \equiv\left(y_{t-1}, \ldots, y_{t-p}\right), \quad X_{t-1} \equiv\left(x_{t-1}, \ldots, x_{t-p}\right), \quad Z_{t}=\left(X_{t}, Y_{t}\right) \quad$ and $\quad F_{y_{t} \mid Z_{t-1}}\left(y_{t}, Z_{t-1}\right) \quad$ and $F_{y_{t} \mid Y_{t-1}}\left(y_{t}, Y_{t-1}\right)$ denote the conditional distribution functions of $y_{t}$ given $Z_{t-1}$ and $Y_{t-1}$, respectively. If we let denote $Q_{\theta}\left(Z_{t-1}\right) \equiv Q_{\theta}\left(y_{t} \mid Z_{t-1}\right)$ and $Q_{\theta}\left(Y_{t-1}\right) \equiv Q_{\theta}\left(y_{t} \mid Y_{t-1}\right)$, we have $F_{y_{t} \mid Z_{t-1}}\left\{Q_{\theta}\left(Z_{t-1}\right) \mid Z_{t-1}\right\}=\theta$ with probability one. As a result, the (non)causality in the -th quantile hypotheses to be tested are:

$$
\begin{aligned}
& H_{0}: P\left\{F_{y_{t} \mid Z_{t 1}}\left\{Q\left(Y_{t 1}\right) \mid Z_{t 1}\right\}=\right\}=1, \\
& H_{1}: \quad P\left\{F_{y_{t} \mid Z_{t 1}}\left\{Q\left(Y_{t 1}\right) \mid Z_{t 1}\right\}=\right\}<1 .
\end{aligned}
$$


Jeong et al. (2012) use the distance measure $J=\left\{\varepsilon_{t} E\left(\varepsilon_{t} \mid Z_{t-1}\right) f_{z}\left(Z_{t-1}\right)\right\}$, where $\varepsilon_{t}$ is the regression error term and $f_{z}\left(Z_{t-1}\right)$ is the marginal density function of $Z_{t-1}$. The regression error $\varepsilon_{t}$ emerges based on the null hypothesis in (1), which can only be true if and only if $E\left[1\left\{y_{t} \leq Q_{\theta}\left(Y_{t-1}\right) \mid Z_{t-1}\right\}\right]=\theta$ or, expressed in a different way, $1\left\{y_{t} \leq Q_{\theta}\left(Y_{t-1}\right)\right\}=\theta+\varepsilon_{t}$, where $\mathbf{1}\{x\}$ is the indicator function. Jeong et al. (2012) show that the feasible kernel-based sample analogue of $J$ has the following format:

$$
\hat{J}_{T}=\frac{1}{T(T \quad 1) h^{2 p}} \sum_{t=p+1}^{T} \sum_{s=p+1, s \neq t}^{T} K\left(\frac{Z_{t 1} Z_{s 1}}{h}\right) \hat{t s} .
$$

where $K(\cdot)$ is the kernel function with bandwidth $h, T$ is the sample size, $p$ is the lag order, and ${ }^{\wedge}$ is the estimate of the unknown regression error, which is given by

$$
\hat{t}=1\left\{y_{t} \quad Q\left(Y_{t 1}\right)\right\} .
$$

$\hat{Q}_{\theta}\left(Y_{t-1}\right)$ is an estimate of the $\theta^{\text {th }}$ conditional quantile of $y_{t}$ given $Y_{t-1}$, and we estimate $\hat{Q}_{\theta}\left(Y_{t-1}\right)$ using the nonparametric kernel method as

$$
\hat{Q}_{\theta}\left(Y_{t-1}\right)=\hat{F}_{y_{t} \mid Y_{t-1}}^{-1}\left(\theta \mid Y_{t-1}\right)
$$

where $\hat{F}_{y_{t} \mid Y_{t-1}}\left(y_{t} \mid Y_{t-1}\right)$ is the Nadarya-Watson kernel estimator given by

$$
\hat{F}_{y_{t} \mid Y_{t 1}}\left(y_{t} \mid Y_{t 1}\right)=\frac{{ }_{s=p+1, s t}^{T} L\left(\left(\begin{array}{ll}
Y_{t 1} & \left.Y_{s 1}\right) / h
\end{array}\right) 1\left(\begin{array}{ll}
y_{s} & y_{t}
\end{array}\right)\right.}{T},
$$

with $L(\cdot)$ denoting the kernel function and $h$ the bandwidth.

As an extension of Jeong et al. (2012)'s framework, Balcilar et al. (2016) develop a test for the second moment which allows us to test the causality between the various disaster risks and exchange rate volatility. Adapting the approach in Nishiyama et al. (2011), higher order quantile causality can be specified in terms of the following hypotheses as: 


$$
\begin{array}{ll}
H_{0}: P\left\{F_{y_{t}^{k} \mid Z_{t 1}}\left\{Q\left(Y_{t 1}\right) \mid Z_{t 1}\right\}=\right\}=1 & \text { for } k=1,2, \ldots, K \\
H_{1}: P\left\{F_{y_{t}^{k} \mid Z_{t 1}}\left\{Q\left(Y_{t 1}\right) \mid Z_{t 1}\right\}=\right\}<1 & \text { for } k=1,2, \ldots, K
\end{array}
$$

We can integrate the entire framework and test whether $x_{t}$ Granger causes $y_{t}$ in quantile $\theta$ up to the $k^{\text {th }}$ moment using Eq. (7) to construct the test statistic in Eq. (6) for each $k$. The causality-in-variance test can then be calculated by replacing $y_{t}$ in Eqs. (3) and (4) with $y_{t}^{2}$ - measuring the volatility of exchange rate returns. However, one can show that it is difficult to combine the different statistics for each $k=1,2, \ldots, K$ into one statistic for the joint null in Eq. (7) because the statistics are mutually correlated (Nishiyama et al., 2011). Balcilar et al. (2016), thus, propose a sequential-testing method as described in Nishiyama et al. (2011). First, as in Balcilar et al. (2016), we test for the nonparametric Granger causality in the first moment (i.e., $k=1$ ). Nevertheless, failure to reject the null for $k=1$ does not automatically lead to no-causality in the second moment. Thus, we can still construct the test for $k=2$, as discussed in detail in Balcilar et al. (2016).

The empirical implementation of causality testing via quantiles entails specifying three key parameters: the bandwidth $(h)$, the lag order $(p)$, and the kernel type for $K(\cdot)$ and $L(\cdot)$. We use a lag order based on the Schwarz information criterion (SIC), which is known to select a parsimonious model as compared with other lag-length selection criteria, and hence, help us to overcome the issue of the over-parameterization that typically arises in studies using nonparametric frameworks. For each quantile, we determine the bandwidth parameter (h) by using the leave-one-out least-squares cross validation method. Finally, for $K(\cdot)$ and $L(\cdot)$, we use Gaussian kernels.

At this stage, it is important to point out that in a bivariate framework, if causality is observed for one step, it holds for all $h>1$ steps (Lütkepohl 1993, 2005). So in a bivariate model, if predictability is observed, it will correspond to infinite-horizon causality. 


\section{Data and Empirical Results}

The empirical analysis utilizes monthly data for dollar-based exchange rates of the BRICS and UK prices and the count on various types of disaster risks. Barring the case of China, the period covered is 1918:01 to 2013:12. In the case of China, we start from 1948:09. The start and end dates for Brazil, Russia, India, South Africa and UK are governed purely by the availability of data on disaster risks. While, in the case of China, the start date corresponds to the availability of data on exchange rates, but the end date is again to match the end point of the variables measuring rare disaster risks. Exchange rate data is sourced from the Global Financial Database, with returns computed as the monthly logarithmic change of exchange rates multiplied by 100 to convert the returns into percentages, and volatility being measured by the squares of these generated returns.

Next we turn our attention to our measure of disaster risks of rare events as obtained from the International Crisis Behavior (ICB) database: https://sites.duke.edu/icbdata. The ICB database covers comprehensive information regarding 464 international political crises that occurred during the period of 1918 to 2013 at monthly frequency, involving 1,036 crisis actors. As per the ICB database, the breakpoint of a crisis is an event, act or changes characterized by following three conditions: (a) a threat to basic value, (b) excessive chances of involvement in military hostilities, and (c) time pressure for response. The ICB database covers comprehensive dimensions of each crisis and we take into account many of these dimensions, following Berkman, et al., (2011, 2017), to analyze the impact of international political risk on exchange rate returns and volatility. The foremost variable of our study is total number of crisis (All Crisis) in any month $t$. Some crisis can be more severe than others, therefore it is expected that more devastating crisis may have stronger effect. Following the Berkman, et al., (2011, 2017), we created the following crisis variables: (1) violent break (Violent Break) includes all the crisis that starts with violent act, (2) violent (Violent) crisis 
includes all the crisis that comprises either serious clashes or full scale war, (3) war (War) includes all the crisis that involves full-scale wars, (4) all crisis that involves grave value threats (Grave Threat), (5) protracted conflicts (Protracted) includes all the crisis with protracted conflict, protracted and crisis outside this conflict, and (6) major power (Major Power) includes the crisis only if at least one superpower or great power is there in both side of conflict. Finally, we also construct a crisis severity index (Crisis Severity Index) that summarizes different aspects of crisis severity into one measure by aggregating the six variables above. For all the above crisis variables, we basically use the monthly count for the risk variables under the various categories.

Figures 1 to 6 presents the findings for BRICS and UK from the causality-in-quantiles tests estimated over the quantile range of 0.10 to 0.90. Panels A and B for each figure present the findings for exchange rate returns and volatility (squared returns) respectively, with the null hypothesis that rare disaster risks does not Granger cause exchange rate returns and volatility. Starting with Brazil, significant causal effect is observed over the entire conditional distribution of returns, with the strongest effect being observed at the quantile of 0.45 . When it comes to volatility, the significant effect is restricted over the lower part of the conditional distribution, i.e., the quantile range of 0.10 to 0.40 , with a peak at $0.10 .{ }^{1}$ As with Brazil, the pattern of the causal effect is similar in China, but the effect covers the entire conditional distribution of its volatility. This is also true when it comes to volatility of the Indian rupee, but in terms of returns, significant causal impact is observed over the quantile range of 0.10 to 0.55. As for Russia, just like in case of China and India, the pattern of the significant impact of rare disaster risks on its exchange rate volatility is similar, while causal impact on the returns is observed over the quantile range of 0.15 to 0.75 , i.e., barring the extreme lower and upper quantiles. As far as South Africa is concerned, the conditional distribution of

\footnotetext{
${ }^{1}$ Note that, the disaster risk variable Wars also has a significant causal impact on volatility at the quantile of 0.75 .
} 
Figure 1(a). Causality-in-Quantiles Test Results for Returns of the Brazilian Real

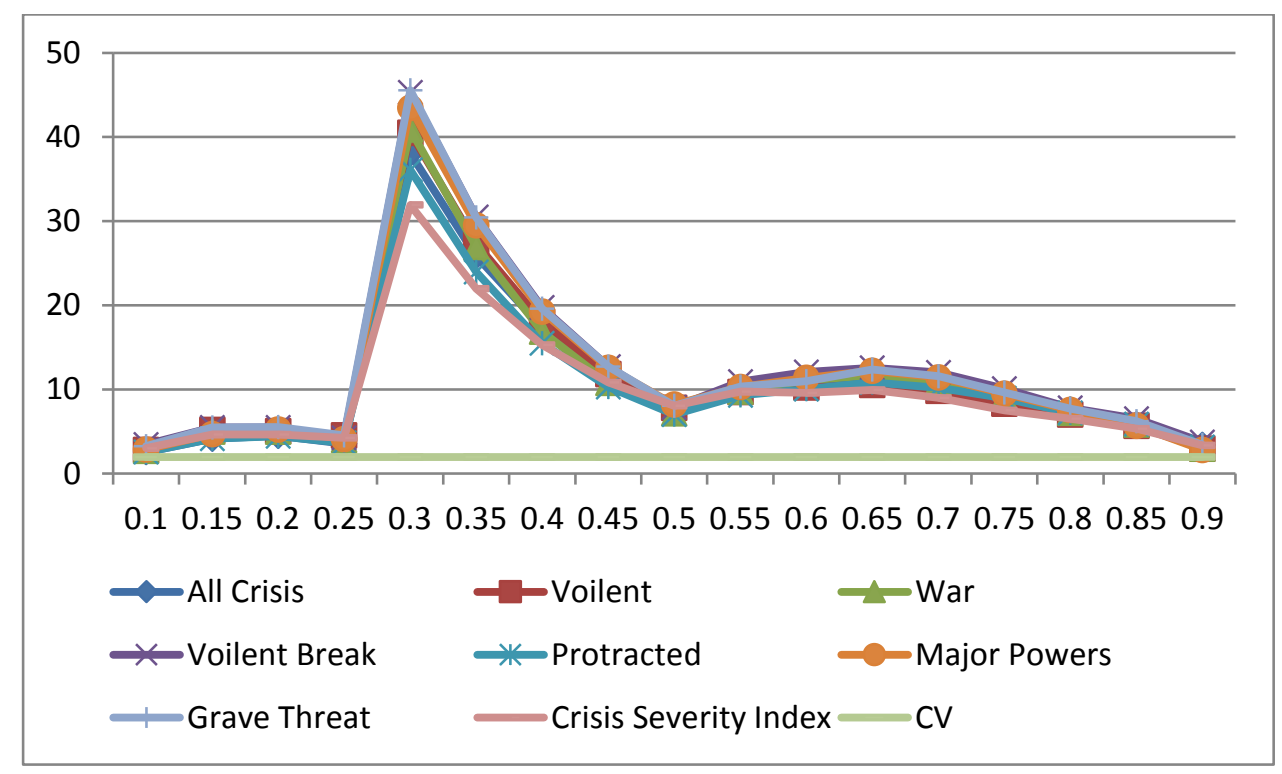

Figure 1(b). Causality-in-Quantiles Test Results for Volatility (Squared Returns) of the Brazilian Real

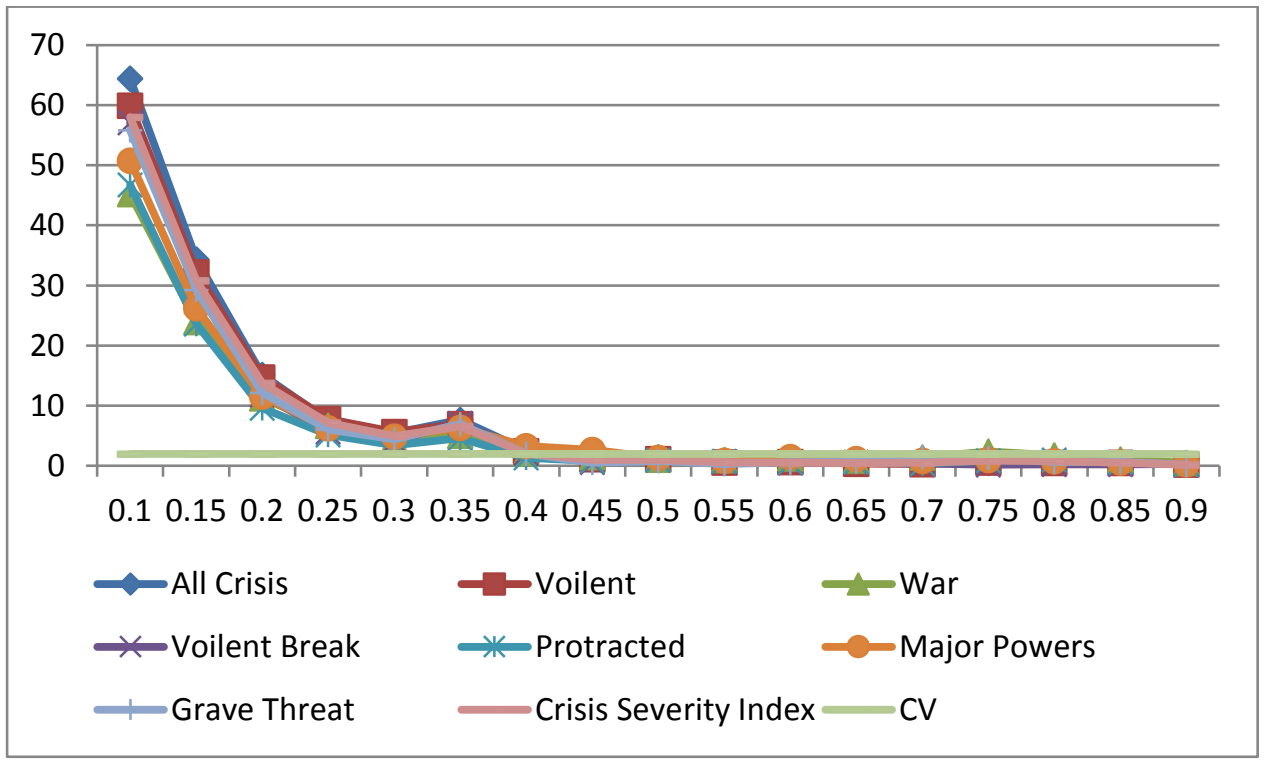

Notes: $\mathrm{CV}$ is the 5 percent critical value of 1.96 . The horizontal axis measures the various quantiles while the vertical axis captures the tests statistic. The lines corresponding to DEALS, DEALS_OIL and DEALS_NONOIL shows the rejection (non-rejection) of the null of no Granger causality from the various measures of disaster risks on exchange rate returns or volatility at the 5 percent level, if the lines are above (below) 1.96 for a specific quantile. 
Figure 2(a). Causality-in-Quantiles Test Results for Returns of the Russian Ruble

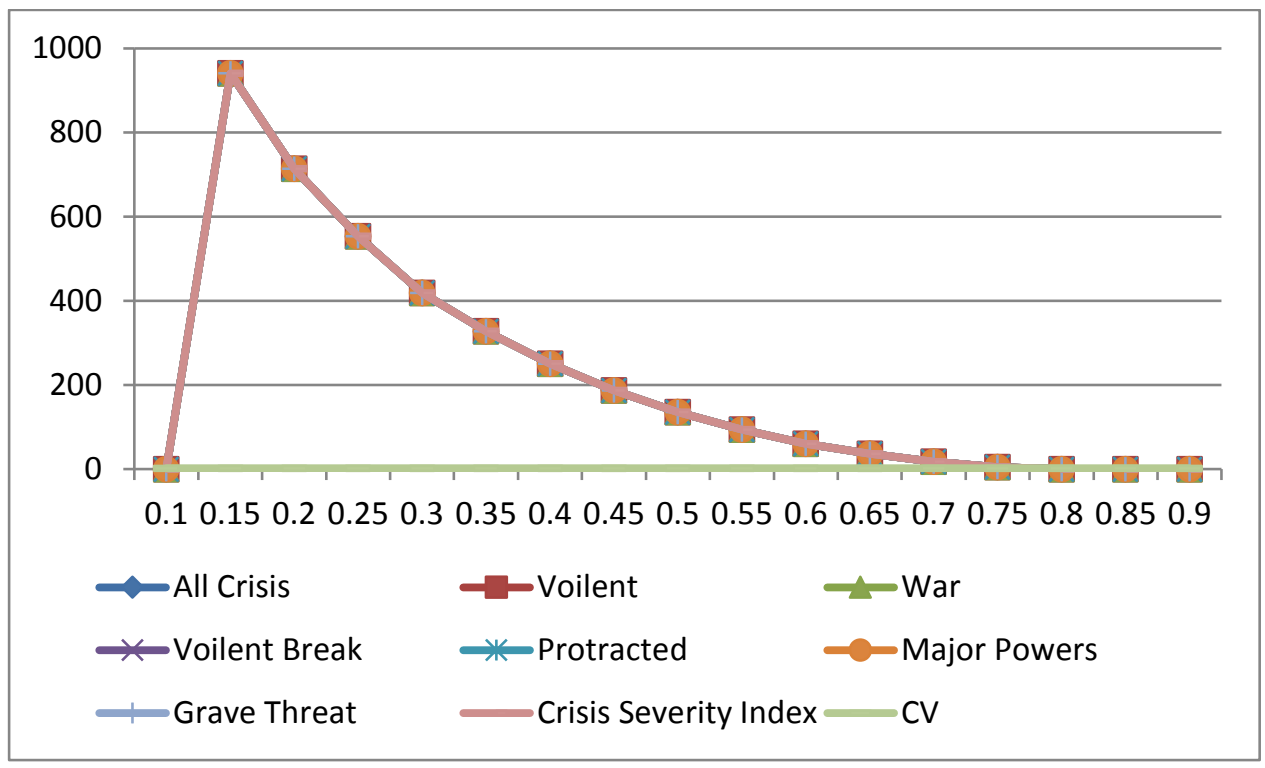

Figure 2(b). Causality-in-Quantiles Test Results for Volatility (Squared Returns) of the Russian Ruble

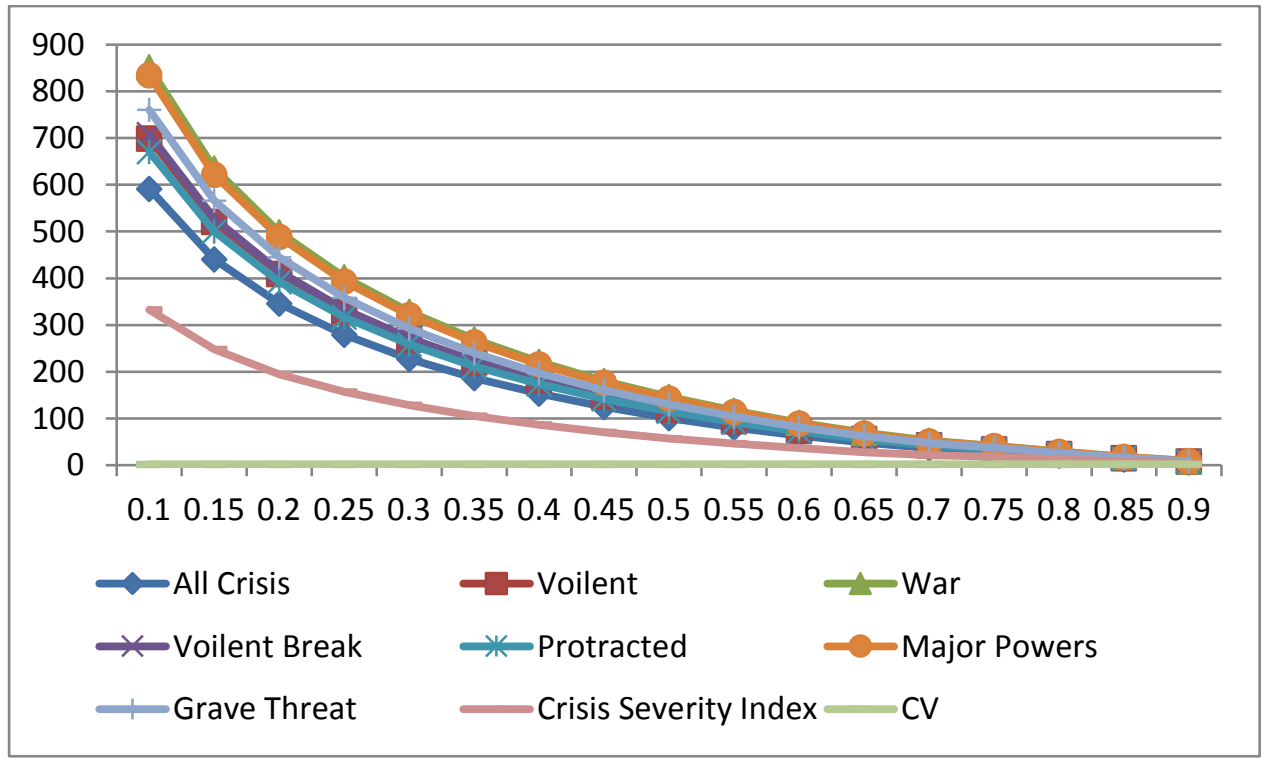

Notes: See Notes to Figure 1. 
Figure 3(a). Causality-in-Quantiles Test Results for Returns of the Indian Rupee

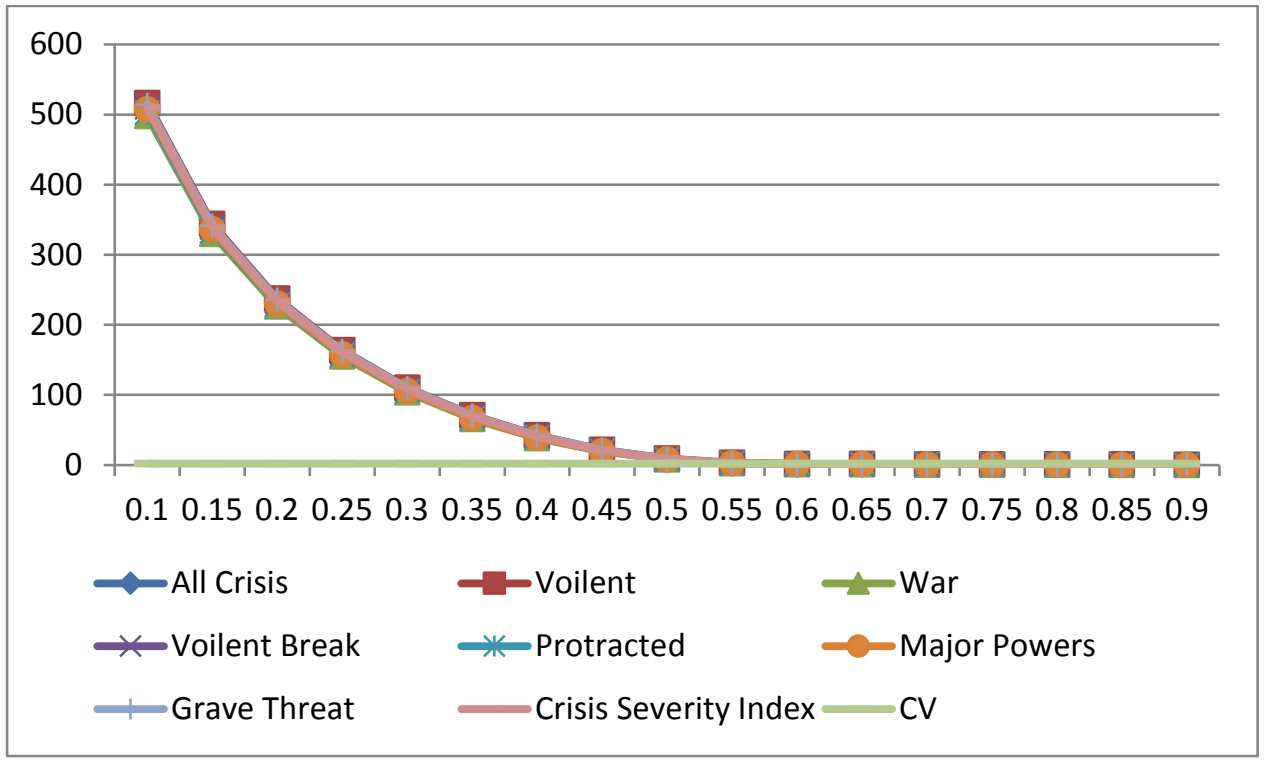

Figure 3(b). Causality-in-Quantiles Test Results for Volatility (Squared Returns) of the Indian Rupee

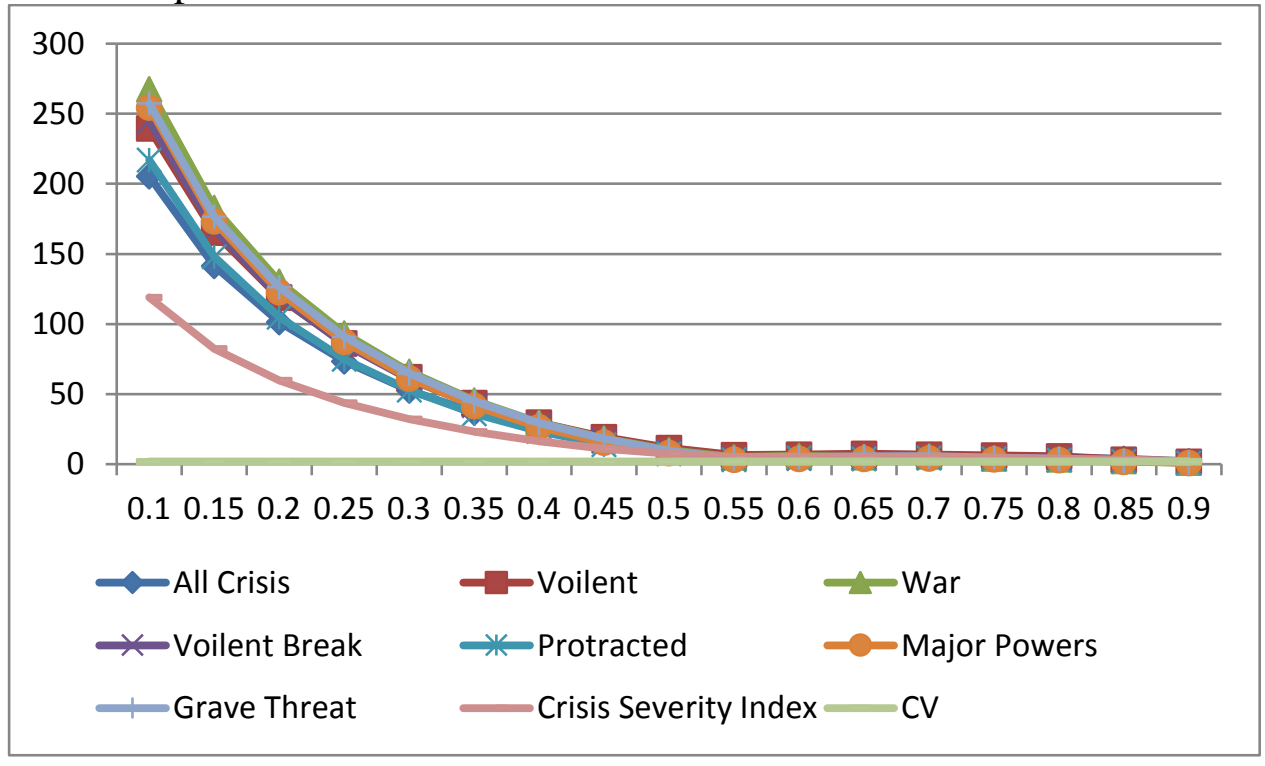

Notes: See Notes to Figure 1. 
Figure 4(a). Causality-in-Quantiles Test Results for Returns of the Chinese Yuan Renminbi

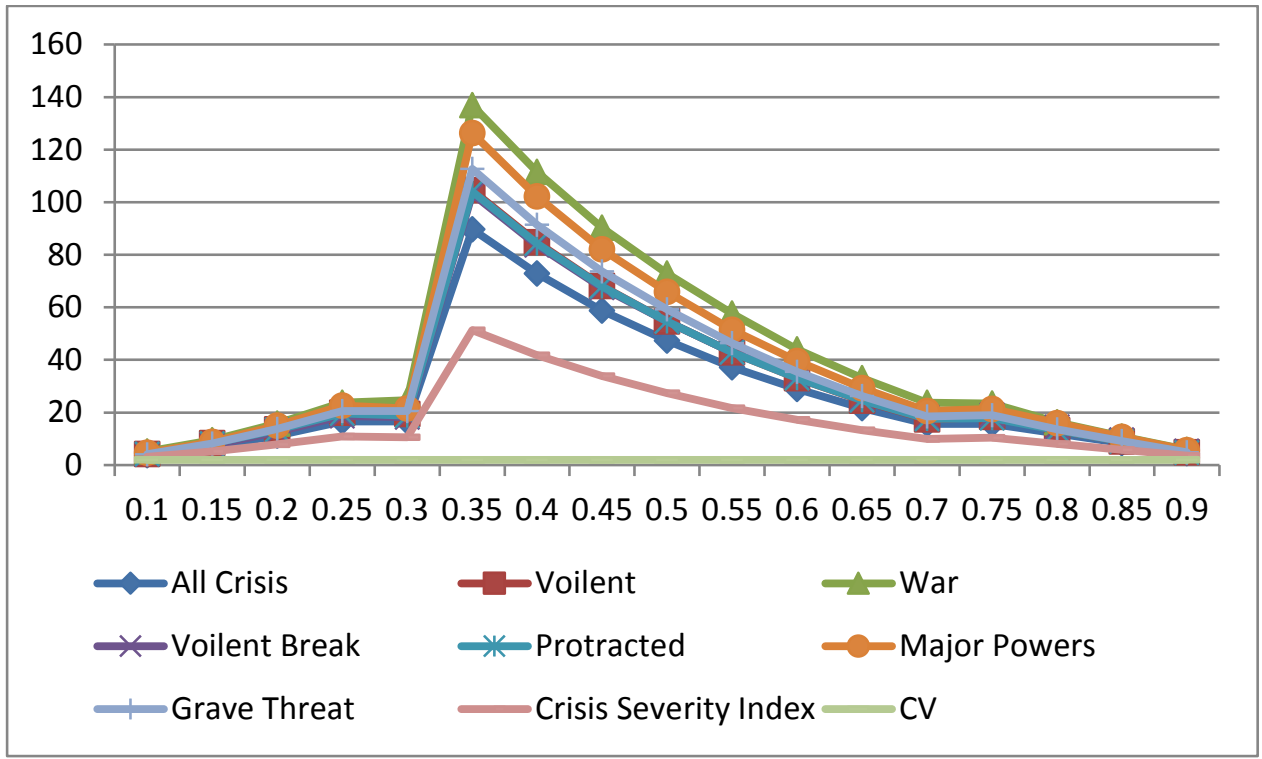

Figure 4(b). Causality-in-Quantiles Test Results for Volatility (Squared Returns) of the Chinese Yuan Renminbi

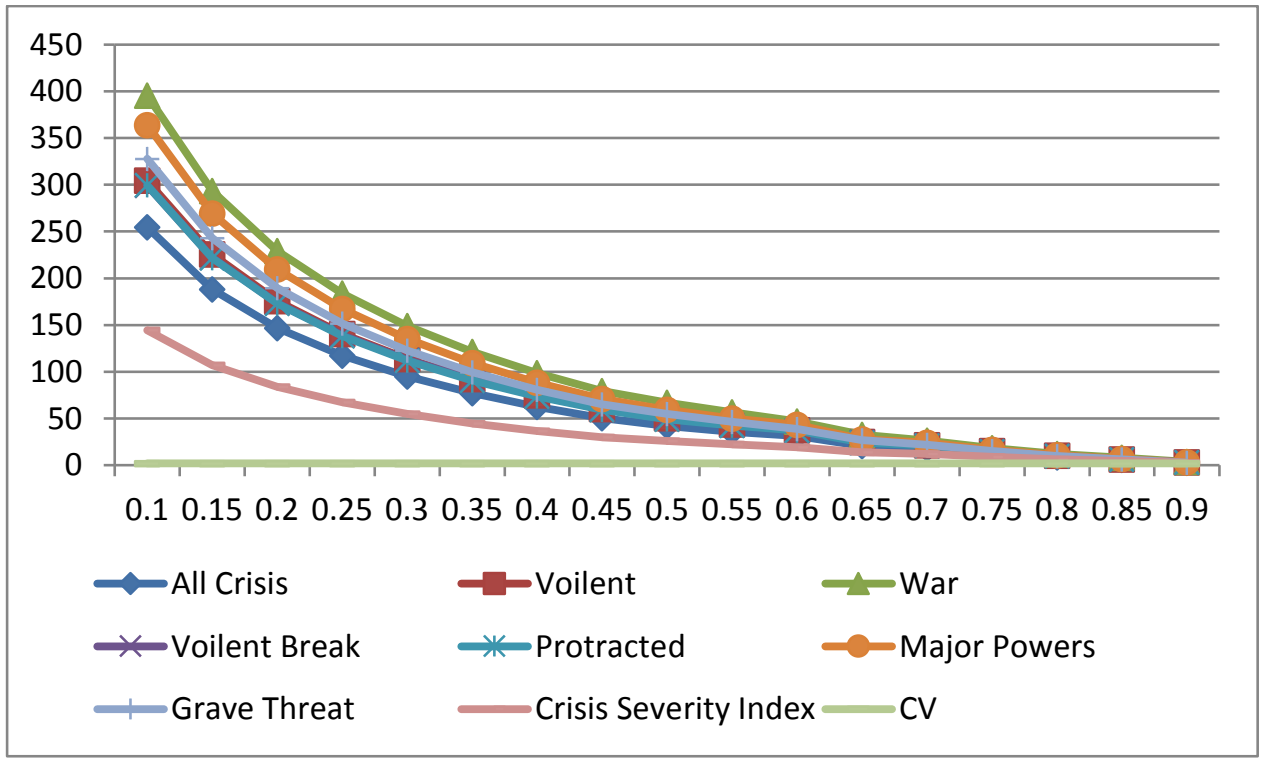

Notes: See Notes to Figure 1. 
Figure 5(a). Causality-in-Quantiles Test Results for Returns of the South African Rand

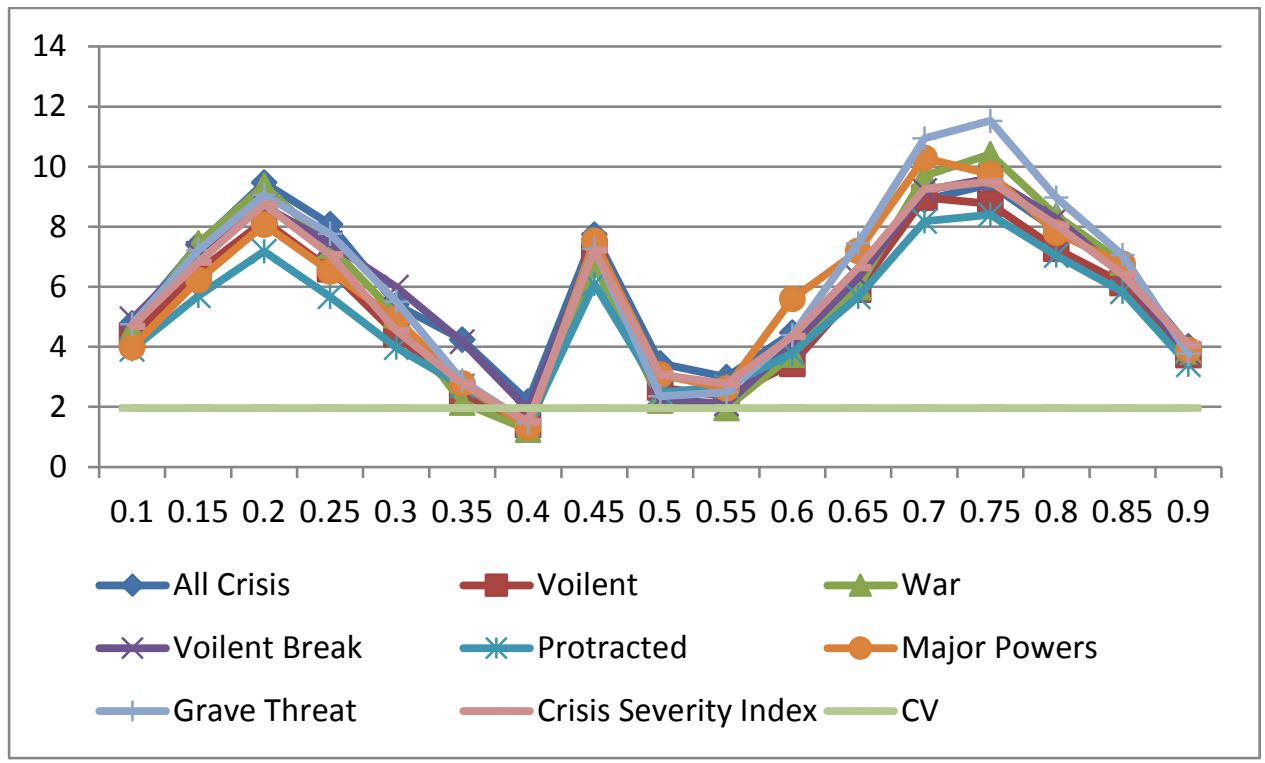

Figure 5(b). Causality-in-Quantiles Test Results for Volatility (Squared Returns) of the South African Rand

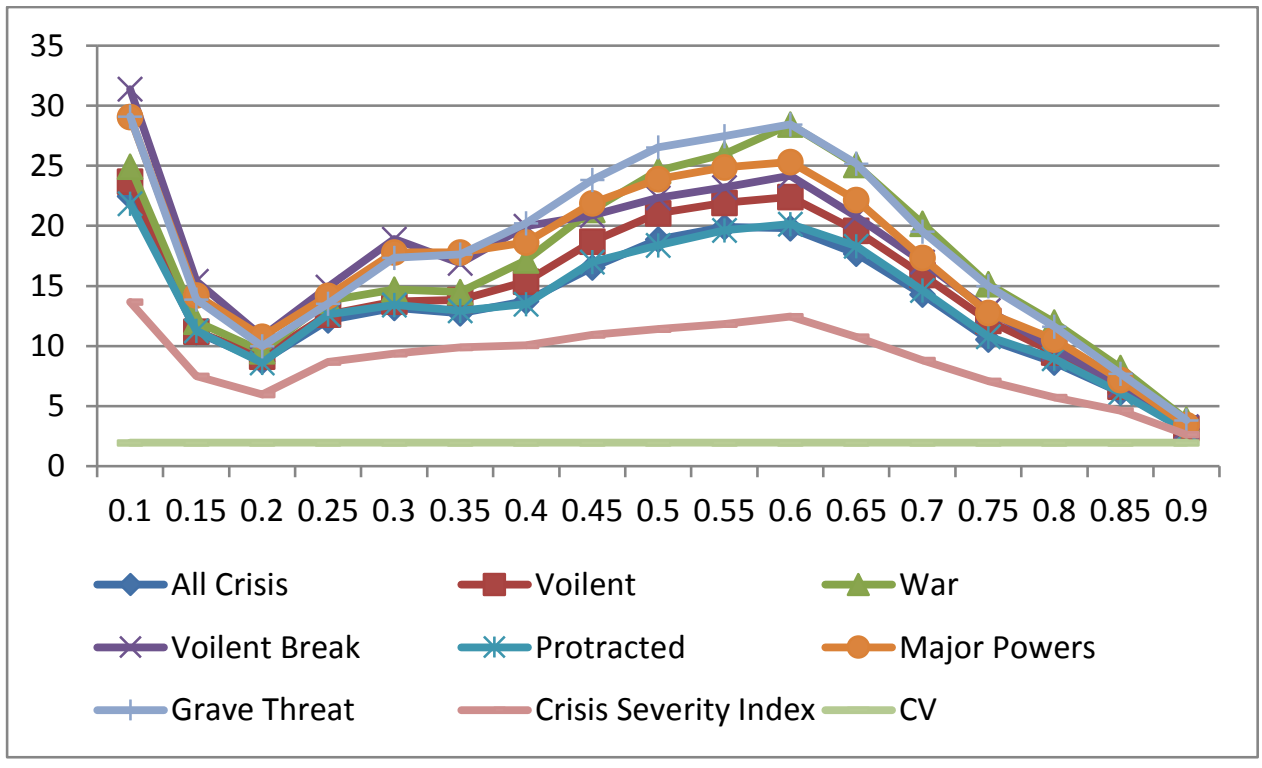

Notes: See Notes to Figure 1. 
Figure 6(a). Causality-in-Quantiles Test Results for Returns of the UK Pound

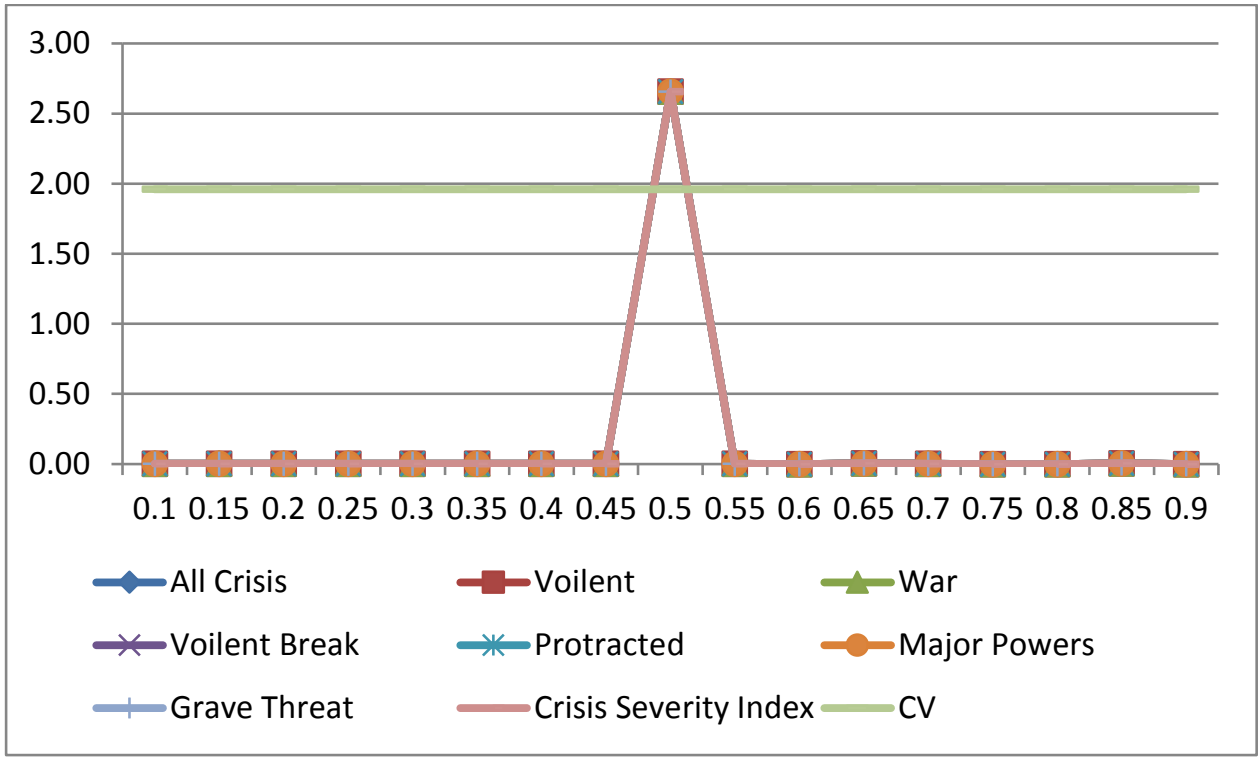

Figure 6(b). Causality-in-Quantiles Test Results for Volatility (Squared Returns) of the UK Pound

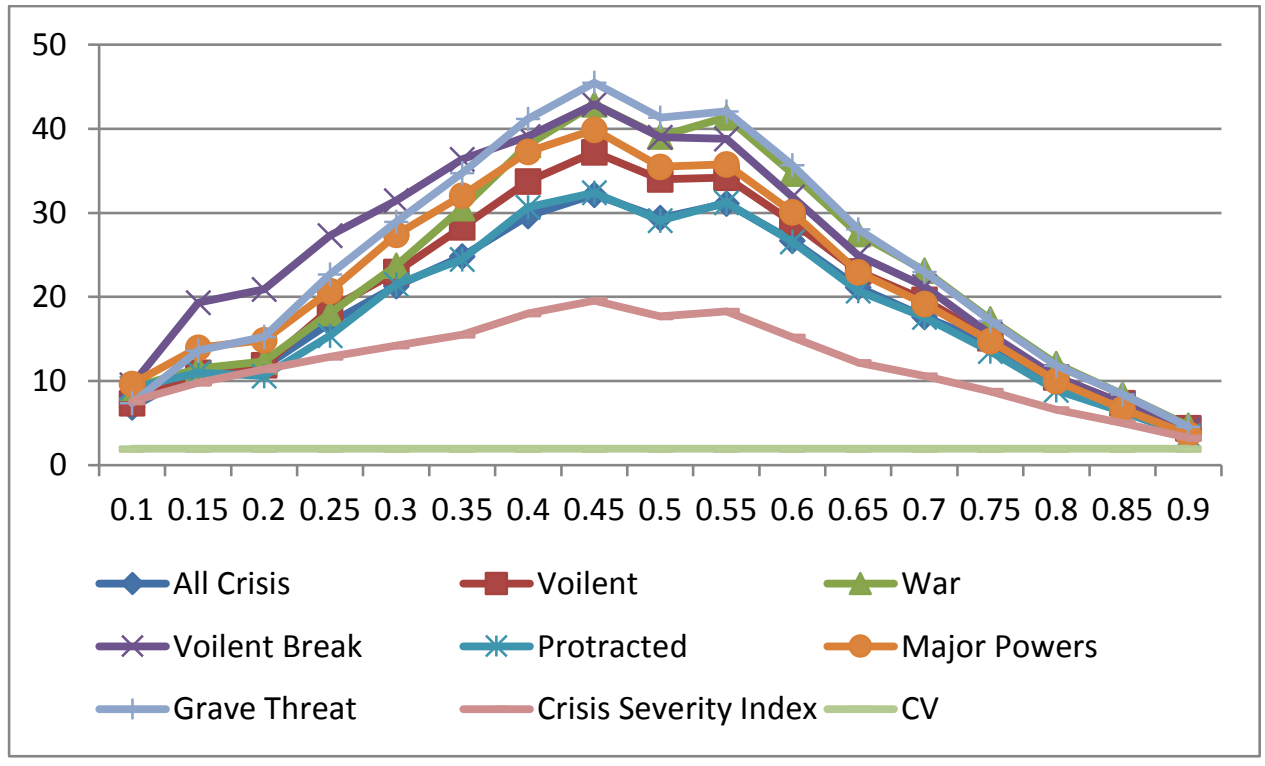

Notes: See Notes to Figure 1.

returns based on the disaster risks is, in general, predicted significantly over the entire conditional distribution, though the strength of the causal effect tends to vary, with the strongest effect observed at the quantile of 0.8 . In terms of the volatility of the rand, as with other countries in the BRICS group, the causal influence is highest at the lowest quantile of 0.10, with it declining thereafter, but then, unlike Brazil, Russia, India and China, the trend is 
reversed for a while at around 0.40 , but declines again from 0.60 . Importantly however, the effect is significant over the entire conditional distribution. When we compare the results of the BRICS with that of the UK, we observe that the disaster variables impact the returns to the pound significantly only around the median. In terms of the volatility, there is clear evidence of causality over the entire conditional distribution, with the peak at the quantile of 0.45 .

In sum, though there is some degree of hetereogeneity across the countries, there is marked homogeneity within a country in terms of the causal effects emanating from the various types of rare disaster risks. We find that rare disaster risks does predict majority of the quantiles of the conditional distributions of returns and volatility for the BRICS. When we look at UK however, the effect on returns is only restricted to the median, though the effect on volatility covers its entire conditional distribution. ${ }^{2}$ More importantly, these results provide strong support for the theoretical propositions emanating from the model of Farhi and Gabaix (2016) on rare disaster risks and exchange rates. This is because, as suggested by the theory, we not only find that rare disaster risks affect returns and volatility of exchange rates, but the effect is particularly strong on returns of the emerging market (BRICS) currencies, since they are perceived to be more risky, when compared to that of the British pound.

\footnotetext{
${ }^{2}$ Based on the suggestion of the Associate Editor, we repeated the analysis using alternative measures of rare disaster risks. In this regard, we used the news-based indexes of total geopolitical risks, and the same due to acts and threats, as recently developed by Caladara and Iacoviello (2018), details of which can be found at: https://www2.bc.edu/matteo-iacoviello/gpr.htm. Caladara and Iacoviello (2018) construct monthly indices of GPRs by counting the occurrence of words related to geopolitical tensions in three leading international newspapers (The New York Times, the Chicago Tribune, and the Washington Post). The authors search for articles containing references to words associated with: explicit mentions of geopolitical risk, as well as mentions of military-related tensions involving large regions of the world and a U.S. involvement; nuclear tensions; war threats and terrorist threats; actual adverse geopolitical events (as opposed to just risks) which can be reasonably expected to lead to increases in geopolitical uncertainty, such as terrorist acts or the beginning of a war. Our results were qualitatively similar to those reported in the paper, and are available upon request from the authors.
} 


\section{Robustness Analysis}

In this segment we conduct some robustness checks of our results. First, the linear Granger causality test results have been reported in Table A1 in the Appendix of the paper. As can be seen, barring the All Crisis variable for Brazil, Russia and the UK, and Grave for Russia, there is no evidence of any predictability emanating from the disaster risks for exchange rate returns, thus pointing towards the weak power of linear causality test in detecting the impact of rare disaster risks on exchange rate movements.

Second, given that over the sample period, the exchange rate regimes of these countries have varied considerably from being fixed, to managed-floating to freely-floating (Ilzetzki et al., 2017), we reconducted the analysis over the post Bretton Woods era, i.e., 1974-2013. ${ }^{3}$ This period does correspond to enhanced degree of flexibility in the exchange rates, though not completely. Our results indicated that the various rare disaster risks does continue to predict the volatility of BRICS exchange rates, while for returns, predictability is restricted only to the BRIC group. For the UK, the evidence continues to be weak, with no predictability for returns, and predictability for volatility around the conditional median due to All Crisis and the Crisis Severity Index. In general, our results seem to be qualitatively in line with the full-sample results, but it must be emphasized that the differences are likely to have been caused by the smaller sample size, given that nonparametric quantiles-based methods do require large number of observations to draw valid inferences. Complete details of these results are available upon request from the authors, but in Tables A2(a) and A2(b), we present the impact of All Crisis and the Crisis Severity Index (given the importance of these two predictors relative to the others) on returns and volatility respectively for the BRICS and the UK.

\footnotetext{
${ }^{3}$ This analysis is based on the suggestion of the Associate Editor.
} 
Note that the objective of this paper was to provide an empirical verification of the theoretical claims made by Farhi and Gabaix (2016) that, rare disaster risks affect exchange rate returns and volatility. Our results are based on an atheoretical model which simply captures the relationship between exchange rate returns or volatility with rare disaster risks in a nonparametric, i.e., data-driven fashion. Given that the theory is silent as to how this relationship is likely to vary across the states of the currency markets, it is indeed difficult for us to exactly pinpoint to the reasons behind the nature of the variation in the strength of predictability over the conditional distributions of the dollar-based exchange rate returns and volatility. In any event, given that the exchange rates in these economies are primarily managed-floating, especially over the bulk of the sample period (see, Ilzetzki et al., (2017)), the behaviour of the exchange rates following rare disaster risks is likely to mirror the monetary policy response. ${ }^{4}$ In general for the BRICS countries, the impact of the rare disaster risks is strongest at lower end of the conditional distribution of volatility (though for South Africa, the effect also seems to pick-up immediately around the quantiles after the median). This could be an indication, that when volatility (risk) in these markets is low, the central banks in these markets do not strongly react in terms of their interest rate, and hence the rare disaster risks tend to have a bigger impact than when we look at the upper quantiles of squared returns, capturing higher volatility, and hence, perhaps stronger monetary policy response. In terms of returns, the strength of the impact or rare disaster risks is less uniform, with Brazil and China showing the strongest impact around moderately lower quantiles, while India and Russia being affected most at lower ends of their respective conditional distributions, and South Africa at moderately low and high quantiles. But barring the case of India, the effects are generally lower at extreme ends of the conditional distribution, with the effects showing a declining trend as the quantiles increase. This result could be an indication

\footnotetext{
${ }^{4}$ We would like to thank the Associate Editor for guiding us in this direction.
} 
that monetary authorities react with their policy tools to nullify the impact of rare disaster risks conditional on the currency experiencing both extreme appreciation (lower quantiles) and deprectations (upper quantiles), but more so in the latter scenario to protect the value of the domestic currency. Unlike the emerging markets, for the UK however, the strongest effects of rare disaster risks on both returns, and volatility in particular, is felt around the median. This could be an indication of the monetary authority to nullify the impact of the disaster risks, except when the currency market is around the normal mode in terms of risk and returns.

\section{Conclusion}

In a recent paper, Farhi and Gabaix (2016) propose a new model of exchange rates, which shows that the possibility of rare but extreme disasters is an important determinant of returns and volatility of exchange rates, with the effect being particularly strong for returns of currencies that are perceived to be more risky. Using a causality-in-quantiles test, which captures higher order causality over the entire conditional distributions of returns and volatility, we provide empirical support of the theoretical propositions of Farhi and Gabaix (2016) by considering the dollar-based exchange rates of the BRICS and UK. This is because of the observation that, while rare disaster-risks affect both returns and volatility over majority of their respective conditional distributions, these effects are much stronger when compared to that on the British pound, especially when it relates to currency returns. As part of future research, it would be interesting to extend our analysis to a forecasting exercise, as in Bonaccolto et al., (2018), since in-sample predictability does not guarantee the same overand out-of-sample. 


\section{References}

Balcilar, M., Bekiros, S., Gupta, R. (2016). The role of news-based uncertainty indices in predicting oil markets: a hybrid nonparametric quantile causality method. Empirical Economics, doi: 10.1007/s00181-016-1150-0.

Barro, R. J. (2006). Rare Disasters and Asset Markets in the Twentieth Century. Quarterly Journal of Economics, 121, 823-866.

Berkman, H., Jacobsen, B., and Lee, J.B. (2011). Time-varying rare disaster risk and stock returns, Journal of Financial Economics, 101, 313-332.

Berkman, H., Jacobsen, B., and Lee, J.B. (2017). Rare disaster risk and the expected equity risk premium, Accounting and Finance, 57(2), 351-372.

Bonaccolto, G., Caporin, M., and Gupta, R. (2018). The dynamic impact of uncertainty in causing and forecasting the distribution of oil returns and risk. Physica A: Statistical Mechanics and its Applications, 507, 446-469..

Caldara, D. and Iacoviello, M. (2018) Measuring Geopolitical Risk. Board of Governors of the Federal Reserve System, International Finance Discussion Paper No. 1222.

Diks, C. G. H., and Panchenko, V. (2005). A note on the Hiemstra-Jones test for Granger noncausality. Studies in Nonlinear Dynamics and Econometrics, 9(2), 1-7.

Diks, C. G. H., and Panchenko, V. (2006). A new statistic and practical guidelines for nonparametric Granger causality testing. Journal of Economic Dynamics and Control, 30(9-10), 1647-1669.

Farhi, E., and Gabaix, X. (2016). Rare Disasters and Exchange Rates, Quarterly Journal of Economics, 131(1), 1-52.

Jeong, K., Härdle, W.K., and Song, S. (2012). A consistent nonparametric test for causality in quantile. Econometric Theory, 28(4), 861-887.

Hiemstra, C., and Jones, J. D. (1994). Testing for linear and nonlinear Granger causality in the stock price-volume relation. Journal of Finance, 49 1639-1664.

Ilzetzki, E., Reinhart, C.M., and Rogoff, K.S. (2017). Exchange Arrangements Entering the 21st Century: Which Anchor Will Hold? NBER Working Paper No. 23134.

Lütkepohl, H. (1993). Testing for causation between two variables in higher dimensional VAR models, in H. Schneeweiß \& K. F. Zimmermann (eds), Studies in Applied Econometrics, Physica, Heidelberg, pp. 75-91.

Lütkepohl, H. (2005). New Introduction to Multiple Time Series, Springer-Verlag: Berlin. 
Mensi, W., Hammoudeh, S., Reboredo, J.C., and Nguyen, D. K. (2014). Do global factors impact BRICS stock markets? A quantile regression approach. Emerging Markets Review, 19(C), 1-17.

Mensi, W., Hammoudeh, S., Yoon, S-M., and Nguyen, D. K. (2016). Asymmetric Linkages between BRICS Stock Returns and Country Risk Ratings: Evidence from Dynamic Panel Threshold Models. Review of International Economics, 24(1), 1-19.

Nishiyama, Y., Hitomi, K., Kawasaki, Y., and Jeong, K. (2011). A consistent nonparametric test for nonlinear causality - Specification in time series regression. Journal of Econometrics, 165, 112-127.

Plakandaras, V., Papadimitriou, T., and Gogas, P. (2015). Forecasting monthly and daily exchange rates with machine learning methodologies. Journal of Forecasting, 34(7), 560573.

Plakandaras, V., Gupta, R., and Wohar M.E. (2017). The depreciation of the pound postBrexit: Could it have been predicted? Finance Research Letters, 21, 206-213.

Rapach, D. E., and Wohar, M. E. (2006). The out-of-sample forecasting performance of nonlinear models of real exchange rate behavior. International Journal of Forecasting, 22, 341-361.

Rietz, T. (1988). The Equity Risk Premium: A Solution. Journal of Monetary Economics, 22, 117-131. 
APPENDIX

Table A1: Linear Granger Causality Test

\begin{tabular}{|c|c|c|c|}
\hline Country & Disaster risk & $\chi^{2}$-statistic & $p$-value \\
\hline \multirow{8}{*}{ Brazil } & All crisis & 7.3389 & $0.0068^{*}$ \\
\hline & Crisis severity index & 2.3934 & 0.1221 \\
\hline & Grave & 3.8076 & 0.0513 \\
\hline & Major Powers & 3.5145 & 0.0611 \\
\hline & Proto & 2.2704 & 0.1321 \\
\hline & Violent Break & 2.9808 & 0.0845 \\
\hline & Violent crisis & 1.5449 & 0.2141 \\
\hline & War & 0.1858 & 0.6665 \\
\hline \multirow{8}{*}{ China } & All crisis & 0.2352 & 0.6278 \\
\hline & Crisis severity index & 0.0738 & 0.7859 \\
\hline & Grave & 2.3531 & 0.1254 \\
\hline & Major Powers & 2.2824 & 0.1313 \\
\hline & Proto & 1.6732 & 0.1962 \\
\hline & Violent Break & 0.0551 & 0.8144 \\
\hline & Violent crisis & 0.6878 & 0.4072 \\
\hline & War & 3.2751 & 0.0707 \\
\hline \multirow{8}{*}{ India } & All crisis & 0.0008 & 0.9774 \\
\hline & Crisis severity index & 0.0009 & 0.9758 \\
\hline & Grave & 0.0843 & 0.7716 \\
\hline & Major Powers & 0.0011 & 0.9730 \\
\hline & Proto & 0.3611 & 0.5480 \\
\hline & Violent Break & 0.0599 & 0.8067 \\
\hline & Violent crisis & 0.4890 & 0.4845 \\
\hline & War & 0.0053 & 0.9420 \\
\hline \multirow{8}{*}{ Russia } & All crisis & 4.2712 & $0.0390 *$ \\
\hline & Crisis severity index & 2.4550 & 0.1174 \\
\hline & Grave & 3.9523 & $0.0470^{*}$ \\
\hline & Major Powers & 1.3635 & 0.2432 \\
\hline & Proto & 0.0247 & 0.8751 \\
\hline & Violent Break & 0.0241 & 0.8766 \\
\hline & Violent crisis & 3.5421 & 0.0601 \\
\hline & War & 0.3139 & 0.5754 \\
\hline \multirow{8}{*}{ South Africa } & All crisis & 0.9947 & 0.3188 \\
\hline & Crisis severity index & 0.8225 & 0.3646 \\
\hline & Grave & 0.7696 & 0.3805 \\
\hline & Major Powers & 0.1807 & 0.6709 \\
\hline & Proto & 0.6896 & 0.4065 \\
\hline & Violent Break & 0.0166 & 0.8975 \\
\hline & Violent crisis & 1.2610 & 0.2617 \\
\hline & War & 0.0618 & 0.8038 \\
\hline \multirow{8}{*}{ United Kingdom } & All crisis & 4.6547 & $0.0312^{*}$ \\
\hline & Crisis severity index & 3.2815 & 0.0703 \\
\hline & Grave & 1.8752 & 0.1711 \\
\hline & Major Powers & 2.4332 & 0.1191 \\
\hline & Proto & 2.3292 & 0.1272 \\
\hline & Violent Break & 0.2307 & 0.6311 \\
\hline & Violent crisis & 2.9653 & 0.0853 \\
\hline & War & 0.0095 & 0.9225 \\
\hline
\end{tabular}

Note: * represents rejection of the null hypothesis of no Granger causality from the various rare disaster risks to exchange rate returns at the $5 \%$ level of significance. 
Table A2(a). Causality-in-Quantiles Test Results for Returns of the BRICS and the UK Dollar-Based Exchange Rates

\begin{tabular}{|c|c|c|c|c|c|c|c|c|c|c|c|c|c|c|c|c|c|c|}
\hline \multirow[t]{2}{*}{ Country } & \multirow[t]{2}{*}{ Disaster risk } & \multicolumn{17}{|c|}{ Quantile } \\
\hline & & 0.1 & 0.15 & 0.2 & 0.25 & 0.3 & 0.35 & 0.4 & 0.45 & 0.5 & 0.55 & 0.6 & 0.65 & 0.7 & 0.75 & 0.8 & 0.85 & 0.9 \\
\hline \multirow[b]{2}{*}{ Brazil } & All crisis & 1.49 & 1.83 & $2.38 *$ & $2.98^{*}$ & $4.25 *$ & $4.40^{*}$ & $4.73^{*}$ & $5.49^{*}$ & $6.21^{*}$ & $6.63^{*}$ & $6.56^{*}$ & $5.57 *$ & $4.41^{*}$ & $3.98 *$ & $3.37 *$ & $2.82 *$ & 1.85 \\
\hline & $\begin{array}{l}\text { Crisis severity } \\
\text { index }\end{array}$ & 1.41 & $2.02 *$ & $2.18^{*}$ & $2.73^{*}$ & $3.64 *$ & $4.01 *$ & $4.29 *$ & $4.80^{*}$ & $5.57 *$ & $5.86^{*}$ & $5.71 *$ & $5.25^{*}$ & $4.16^{*}$ & $3.69 *$ & $3.32 *$ & $2.48^{*}$ & $2.03 *$ \\
\hline \multirow[b]{2}{*}{ Russia } & All crisis & $1.96^{*}$ & $3.91 *$ & $5.19^{*}$ & $65.14 *$ & $52.17 *$ & $42.05^{*}$ & $33.81 *$ & $27.08 *$ & $21.38^{*}$ & $16.66^{*}$ & $12.89^{*}$ & $9.92 *$ & $8.68^{*}$ & $6.48^{*}$ & $4.84 *$ & $3.54 *$ & $2.20^{*}$ \\
\hline & $\begin{array}{l}\text { Crisis severity } \\
\text { index }\end{array}$ & $2.47 *$ & $4.24 *$ & $5.07 *$ & $36.56^{*}$ & $29.26^{*}$ & $23.57 *$ & 18.98* & $15.29 *$ & $12.28 *$ & $9.74 *$ & $7.85^{*}$ & $6.38^{*}$ & $5.68^{*}$ & $4.72 *$ & $3.99 *$ & $3.26^{*}$ & $2.46^{*}$ \\
\hline \multirow{2}{*}{ India } & All crisis & $3.07 *$ & $4.10 *$ & $4.86^{*}$ & $5.33^{*}$ & $5.82 *$ & $6.27 *$ & $7.86^{*}$ & $8.12^{*}$ & $9.13^{*}$ & $10.31^{*}$ & $9.33^{*}$ & $7.61^{*}$ & 7.84* & $6.75^{*}$ & $5.51^{*}$ & $4.43^{*}$ & $3.10^{*}$ \\
\hline & $\begin{array}{l}\text { Crisis severity } \\
\text { index }\end{array}$ & $3.09 *$ & $3.87 *$ & $4.71^{*}$ & $6.32^{*}$ & $6.33 *$ & $5.83^{*}$ & $5.80^{*}$ & $6.55^{*}$ & $7.49^{*}$ & $8.15^{*}$ & $8.21 *$ & $6.96^{*}$ & $6.22 *$ & $5.54^{*}$ & $4.58^{*}$ & $3.80^{*}$ & $2.80^{*}$ \\
\hline \multirow[b]{2}{*}{ China } & All crisis & $2.38^{*}$ & $4.25 *$ & $6.75^{*}$ & $7.42 *$ & $8.32 *$ & $8.62 *$ & $6.41^{*}$ & $4.85^{*}$ & $3.66^{*}$ & $3.92 *$ & $2.53 *$ & $3.24 *$ & $4.48^{*}$ & $6.13^{*}$ & $6.63^{*}$ & $4.78^{*}$ & $2.69^{*}$ \\
\hline & $\begin{array}{l}\text { Crisis severity } \\
\text { index }\end{array}$ & $2.46^{*}$ & $3.84 *$ & $5.38^{*}$ & $6.47^{*}$ & $7.29 *$ & $7.42 *$ & $5.73^{*}$ & $4.44^{*}$ & $3.61^{*}$ & $4.91 *$ & $3.77^{*}$ & $5.00^{*}$ & $5.46^{*}$ & $5.41^{*}$ & $4.97 *$ & $3.77 *$ & $2.44^{*}$ \\
\hline \multirow{2}{*}{$\begin{array}{l}\text { South } \\
\text { Africa }\end{array}$} & All crisis & 0.35 & 0.39 & 0.43 & 0.41 & 0.23 & 0.16 & 0.08 & 0.08 & 0.16 & 0.18 & 0.18 & 0.26 & 0.29 & 0.28 & 0.23 & 0.20 & 0.16 \\
\hline & $\begin{array}{l}\text { Crisis severity } \\
\text { index }\end{array}$ & 0.42 & 0.57 & 0.67 & 0.64 & 0.41 & 0.28 & 0.15 & 0.05 & 0.14 & 0.16 & 0.17 & 0.22 & 0.25 & 0.24 & 0.26 & 0.19 & 0.19 \\
\hline \multirow{2}{*}{$\begin{array}{c}\text { United } \\
\text { Kingdom }\end{array}$} & All crisis & 0.38 & 0.27 & 0.25 & 0.39 & 0.33 & 0.24 & 0.18 & 0.19 & 0.23 & 0.11 & 0.08 & 0.07 & 0.06 & 0.11 & 0.13 & 0.17 & 0.11 \\
\hline & $\begin{array}{l}\text { Crisis severity } \\
\text { index }\end{array}$ & 0.26 & 0.21 & 0.20 & 0.31 & 0.33 & 0.34 & 0.28 & 0.33 & 0.42 & 0.19 & 0.13 & 0.21 & 0.05 & 0.05 & 0.07 & 0.10 & 0.08 \\
\hline
\end{tabular}

Note: * represents rejection of the null hypothesis of no Granger causality from the rare disaster risks to exchange rate returns across various quantiles at the $5 \%$ level of significance. 
Table A2(b). Causality-in-Quantiles Test Results for Volatility (Squared Returns) of the BRICS and the UK Dollar-Based Exchange Rates

\begin{tabular}{|c|c|c|c|c|c|c|c|c|c|c|c|c|c|c|c|c|c|c|}
\hline \multirow[t]{2}{*}{ Country } & \multirow[t]{2}{*}{ Disaster risk } & \multicolumn{17}{|c|}{ Quantile } \\
\hline & & 0.1 & 0.15 & 0.2 & 0.25 & 0.3 & 0.35 & 0.4 & 0.45 & 0.5 & 0.55 & 0.6 & 0.65 & 0.7 & 0.75 & 0.8 & 0.85 & 0.9 \\
\hline \multirow[b]{2}{*}{ Brazil } & All crisis & 0.78 & 1.00 & 1.44 & 1.36 & 1.87 & 1.94 & 1.69 & $1.96^{*}$ & 1.19 & 1.20 & 1.12 & 1.13 & 1.02 & 1.46 & 1.63 & 1.08 & 1.09 \\
\hline & $\begin{array}{l}\text { Crisis } \\
\text { severity index }\end{array}$ & 1.33 & $2.18 *$ & $2.28^{*}$ & $2.12 *$ & $2.52 *$ & $3.12 *$ & $2.69 *$ & $3.33 *$ & $2.52 *$ & $2.76^{*}$ & $2.65 *$ & $2.56^{*}$ & $2.66^{*}$ & $2.88^{*}$ & $2.81 *$ & $1.96^{*}$ & 1.95 \\
\hline \multirow{2}{*}{ Russia } & All crisis & 132.99* & $98.68 *$ & 77.17* & 61.90* & $50.30 *$ & $41.10^{*}$ & $33.63 *$ & $28.02 *$ & $23.47 *$ & $20.83^{*}$ & 16.64* & $14.01 *$ & $10.96^{*}$ & $8.05 *$ & $6.04 *$ & $4.06^{*}$ & $2.38 *$ \\
\hline & $\begin{array}{l}\text { Crisis } \\
\text { severity index }\end{array}$ & $76.04 *$ & $56.45^{*}$ & $44.22 *$ & $35.58^{*}$ & $29.06^{*}$ & $23.94 *$ & $19.83 *$ & $16.73^{*}$ & $14.49 *$ & $13.97 *$ & $11.71 *$ & $10.15^{*}$ & $8.27 *$ & $6.48^{*}$ & $5.29 *$ & $3.96^{*}$ & $2.67 *$ \\
\hline \multirow{2}{*}{ India } & All crisis & 1.57 & $2.41 *$ & 1.88 & $2.41 *$ & $8.50 *$ & $7.40 *$ & $5.63 *$ & $4.42 *$ & $3.35 *$ & $2.94 *$ & $2.84 *$ & $2.11 *$ & 1.28 & 1.11 & 0.70 & 0.52 & 0.47 \\
\hline & $\begin{array}{l}\text { Crisis } \\
\text { severity index }\end{array}$ & $2.30 *$ & $3.19 *$ & $2.65^{*}$ & $3.94 *$ & $6.85 *$ & $6.28 *$ & $5.03 *$ & $3.81 *$ & $3.69 *$ & $3.19 *$ & $2.96 *$ & $2.89 *$ & $2.19 *$ & 1.38 & 1.20 & 0.86 & 0.66 \\
\hline \multirow{2}{*}{ China } & All crisis & $9.15 *$ & $4.95 *$ & $5.98^{*}$ & $8.99 *$ & $11.41 *$ & $16.05^{*}$ & $19.42 *$ & $20.08^{*}$ & $19.60 *$ & $19.15^{*}$ & $16.91 *$ & 14.92* & $11.18^{*}$ & $8.55^{*}$ & $5.86^{*}$ & $4.11^{*}$ & $2.45 *$ \\
\hline & $\begin{array}{l}\text { Crisis } \\
\text { severity index }\end{array}$ & $10.02 *$ & $6.12 *$ & $8.16^{*}$ & $10.36^{*}$ & $11.73 *$ & $14.04 *$ & $15.96^{*}$ & $15.79 *$ & $15.21 *$ & $14.18^{*}$ & 11.93* & $10.34 *$ & 8.17 * & $6.42 *$ & $4.66^{*}$ & $3.56^{*}$ & $2.38 *$ \\
\hline \multirow{2}{*}{$\begin{array}{l}\text { South } \\
\text { Africa }\end{array}$} & All crisis & 1.34 & 1.30 & 1.15 & 1.48 & 1.12 & 1.63 & 1.89 & $2.23 *$ & $2.02 *$ & $2.32 *$ & $2.44 *$ & $3.19 *$ & $2.75^{*}$ & $2.65 *$ & $2.45 *$ & $2.69^{*}$ & $2.14 *$ \\
\hline & $\begin{array}{l}\text { Crisis } \\
\text { severity index }\end{array}$ & 1.42 & 1.17 & 1.35 & 1.55 & 1.50 & 1.78 & $2.33^{*}$ & $2.01 *$ & $1.98 *$ & $2.41 *$ & $2.34 *$ & $3.24 *$ & $3.22 *$ & $3.35^{*}$ & $2.99 *$ & $3.61 *$ & $2.85 *$ \\
\hline \multirow{2}{*}{$\begin{array}{c}\text { United } \\
\text { Kingdom }\end{array}$} & All crisis & 0.96 & 0.95 & 1.54 & 1.89 & 1.72 & 1.77 & 1.66 & $2.12 *$ & $2.57 *$ & $3.27 *$ & $2.92 *$ & $2.88 *$ & $3.19 *$ & $2.72 *$ & $2.66^{*}$ & $2.24 *$ & 1.33 \\
\hline & $\begin{array}{l}\text { Crisis } \\
\text { severity index }\end{array}$ & 1.88 & 1.73 & 1.80 & $2.15^{*}$ & $1.98 *$ & $2.01 *$ & $2.00 *$ & $2.52 *$ & $2.56^{*}$ & $3.18 *$ & $3.09 *$ & $2.97 *$ & $3.07 *$ & $2.60 *$ & $2.34 *$ & 1.77 & 1.11 \\
\hline
\end{tabular}

Note: * represents rejection of the null hypothesis of no Granger causality from the rare disaster risks to exchange rate volatility across various quantiles at the $5 \%$ level of significance. 